\title{
DINÂMICA DA REPRODUÇÃO DO CASCUDO, RINELORICARIA LATIROSTRIS BOULENGER (SILURIFORMES, LORICARIIDAE) DO RIO PASSA CINCO, IPEÚNA, SÃO PAULO
}

\author{
Geraldo Barbieri $^{1}$
}

\begin{abstract}
REPRODUCTION DYNAMICS OF RINELORICARIA LATIROSTRIS BOULENGER (Siluriformes, loricarildae) of the Passa Cinco River, Ipeúna, São Paulo. Aspects of reproduction of Rineloricaria latirostris Boulenger, 1899 of Passa Cinco river (Ipeúna, São Paulo) were investigated during 18 months. The spawing period was determined by the analysis of the maturation curve, based of the monthly variation of the gonadosomatic index and condition factor. The size and age on the maturation and fecundity were also determined. The fecundity was realted to some parameters such as total length and total weight.
\end{abstract}

KEY WORDS. Reproduction, dynamics, maturation, fecundity

Rineloricaria latirostris Boulenger, 1899, conhecida regionalmente como "cascudo-viola", é um representante de Loricariidae muito abundante no ecossistema rio Passa Cinco (Ipeúna, São Paulo). Os representantes desta família possuem corpo recoberto de placas ósseas em várias séries, lábios alargados em forma de ventosa e maxilas providas de uma série de dentículos com dois lobos desiguais adaptados a raspar algas do substrato (BRITSKI 1972). Rineloricaria Boulenger, 1899 apresenta parede ventral do corpo provida de placas e margem da cabeça revestida de numerosas cerdas nos machos e com placa grande à frente do ânus (BRITSKI 1972; BRITSKI et al. 1988). Segundo GERY (1969) e LOWE MCCONNELL (1975), os representantes desse grupo se restringem à Ámerica do Sul. No rio Passa Cinco habitam trecho rochoso, lótico de corredeira com fundo pedregoso e de pouca profundidade.

Em se tratando de peixe iliófago (ANGELESCU \& GNERI 1949; GNERI \& ANGELESCU 1951), ele exerce papel importante nesse ecossitema pois, atua na matéria orgânica do lodo na fase de pré-mineralização, fornecendo às bactérias um substrato mais facilmente decomponível. Graças a essa ação contribui na reciclagem de nutrientes, aumentando a produtividade do ecossistema e facilitando o processo de depuração do manancial. As características ambientais descritas por MOREIRA FILHO (1983) justificam a grande variedade de Loricariidae no rio Passa Cinco, alguns ainda não identificados do ponto de vista taxonômico.

O presente trabalho fez parte de um estudo global sobre a biologia e auto-ecologia de peixes do rio Passa Cinco (Ipeúna, São Paulo) e visou analisar aspectos quantitativos da dinâmica reprodutiva do "cascudo-viola", Rineloricaria

1) Laboratório de Ictiologia, Departamento de Hidrobiologia, Universidade Federal de São Carlos, Caixa Postal 676, 13565-905 São Carlos, São Paulo, Brasil. Bolsista do CNPq. 
latirostris, no que diz respeito à determinação da época de reprodução, tipo de desova, tamanho e idade de primeira maturação gonadal e fecundidades absoluta e relativa.

\section{MATERIAL E MÉTODOS}

\section{Coleta de dados}

Para o desenvolvimento do presente trabalho foram coletados 566 exemplares (234 machos e 332 fêmeas) no rio Passa Cinco no período de maio de 1991 a outubro de 1992. De cada exemplar foram registrados o sexo, comprimento total $(\mathrm{Lt})$ em centímetros, o peso total (Wt) em gramas, peso das gônadas $(\mathrm{wg})$ em gramas e coletados os três pares de otólitos. Os estádios de maturação gonadal foram estabelecidos macro e microscopicamente segundo CARAMASCHI (1979), BARBIERI (1981) e AGOSTINHO (1985) e assim classificados: I) jovem, imaturo; II) em maturação 1, 2 e 3; III) maduro 1, 2, 3; e IV) parcial e totalmente esgotado. Não foi observada a ocorrência do estádio de repouso. Os ovários destinados à análise do tipo de desova e fecundidade foram seccionados e mergulhados em solução de Gilson modificada (SIMPSON 1951, 1959) para separação dos ovócitos. Em função da baixa fecundidade apresentada e do tamanho do diâmetro, todos os ovócitos foram contados e medidos. Para a determinação dos estádios de maturação gonadal foram considerados caracteres macroscópicos (tamanho, coloração da gônada e no caso dos ovários o tamanho dos ovócitos intra-ováricos) e microscópicos.

Os três pares de otólitos foram preparados segundo procedimento descrito em RiCKER (1971) e VAZzoler (1981) e a leitura dos anéis segundo metodologia apresentada em JONES \& HYNES (1950) e FENERICH et al. (1975). O par "lapillus" de otólitos mostrou ser o mais apropriado para a leitura dos anéis.

\section{MÉTOdOS DE ANÁLISES DOS DADOS}

A época de reprodução foi definida pela análise da curva de maturação baseada na variação temporal do índice gonadossomático (IGS) e do fator de condição (Ø), segundo metodologias descritas em SANTOS (1978) e VAZZOLER (1981). O tipo de desova foi estabelecido através da observação histológica das gônadas e graficamente pela distribuição dos diâmetros dos ovócitos para cada estádio de maturação gonadal, definido em função do tempo.

A fecundidade absoluta foi estimada através da contagem total dos ovócitos em ovários com avançado estádio de maturação $(n=35)$. Foram estabelacidas as relações da fecundidade com o comprimento total dos exemplares, peso total das fêmeas e peso dos ovários.

O tamanho de primeira maturação gonadal foi considerado aquele em que $50 \%$ dos indivíduos da população foram classiticados como adultos (estádios II, III e IV). A idade dos exemplares foi estabelecida pelo método dos anéis etários nos otólitos, sendo as curvas de crescimento ajustadas pela expressão de Bertalanffy (BERTALANFFY 1938), após constatação de sua validade pela transformação Ford-Walford (WALFORD 1946). 


\section{RESULTADOS E DISCUSSÃO}

Os estudos sobre dinâmica da reprodução ocupam importante lugar na Investigação Pesqueira por fornecerem subsídios necessários para a elaboração de programas visando a exploração racional e preservação das espécies ícticas de nossos rios e lagos. Dentro dessa linha de pesquisa destaca-se aspectos como época de reproduçõ, tamanho e idade de primeira maturação gonadal, fecundidade, taxa de crescimento e tipo de desova.

As gônadas de Rineloricaria latirostris do rio Passa Cinco apresentam característiscas micro e macroscópicas semelhantes às descritas para outros Loricariidae. A escala de maturação para a espécie foi elaborada com nove estádios. A análise da curva de maturação (Figs 1 A, 1B, 1C) sugere que o período reprodutivo é longo e ocorre principalmente nos meses de setembro-outubro com menor intensidade nos meses de julho-agosto e novembro-dezembro. Essa análise quando associada às observações microscópicas e com a curva de distribuição de diâmetros de ovócitos (Fig. 2) indica que a espécie apresenta desova parcelada, com três lotes de ovócitos vitelinados e de tamanhos distintos. Os ovócitos maduros apresentam diâmetro grande, ao redor de $4000 \mu \mathrm{m}$. Características semelhantes foram observadas nos estudos com o cascudo Hypostomus aff. plecostomus Linnaeus, 1758 da represa do Monjolinho (BARBIERI et al. 1988) e o cascudo preto Hypostomus sp. do rio Passa Cinco (BARBIERI \& BARBIERI 1992).

A distribuição de freqüência de diâmetros de ovócitos tem sido amplamente utilizada em Investigação Pesqueira mas essa análise quando usada em espécies que apresentam comportamento polimodal tem sido questionada por alguns autores. Agostinho (1985) apresentou uma análise crítica sobre o assunto através de ampla revisão bibliográfica. A crítica enfatiza os riscos de se estabelecer arbitrariamente os intervalos de classes de diâmetros, além da dificuldade de se prever quando os ovócitos vitelinados de diâmetros menores serão eliminados ou reabsorvidos. BEGENAL (1978) sugeriu que além desse estudo o pesquisador deveria levar em consideração também a ocorrência ou não de sincronismo dos ovócitos, além de outros parâmetros como variação do índice gonadossomático, fator de condição, etc. Segundo esse autor, baixos valores do índice no final do período reprodutivo tem sido considerado uma das características de espécies que apresentam desova parcelada.A espécie em estudo apresentou esse comportamento. Da mesma forma, a utilização isolada da variação do fator de condição também tem sido questionada pois nela também podem interferir outras variáveis como acúmulo de gordura, suscetibilidade às mudanças ambientais, grau de repleção do estômago e desenvolvimento gonadal (LE CREN 1951). BRAGA et al. (1985) relacionaram o valor do fator de condição com o aumento do comprimento do peixe e MCGREGOR (1959) com a densidade populacional. Segundo este autor, altos níveis populacionais resultam em menor disponibilidade alimentar e portanto, menor valor no fator de condição. VAZZOLER \& VAZZOLER (1965) sugerem a utilização da "condição gonadal", estimada a partir da diferença do fator de condição calculado com o peso total dos exemplares e sem o peso da gonada. BARBIERI \& VERANI (1987) constataram que essa metodologia apresentou resul- 
tados satisfatórios nos estudos com o cascudo Hypostomus aff. plecostomus da represa do Monjolinho. Narahara (1983) e Agostinho (1985) recomendam ainda a observação da frę̧üência de exemplares semi-esgotados na população como outra estratégia que pode colaborar na definição do tipo de desova de uma determinada espécie de peixe.

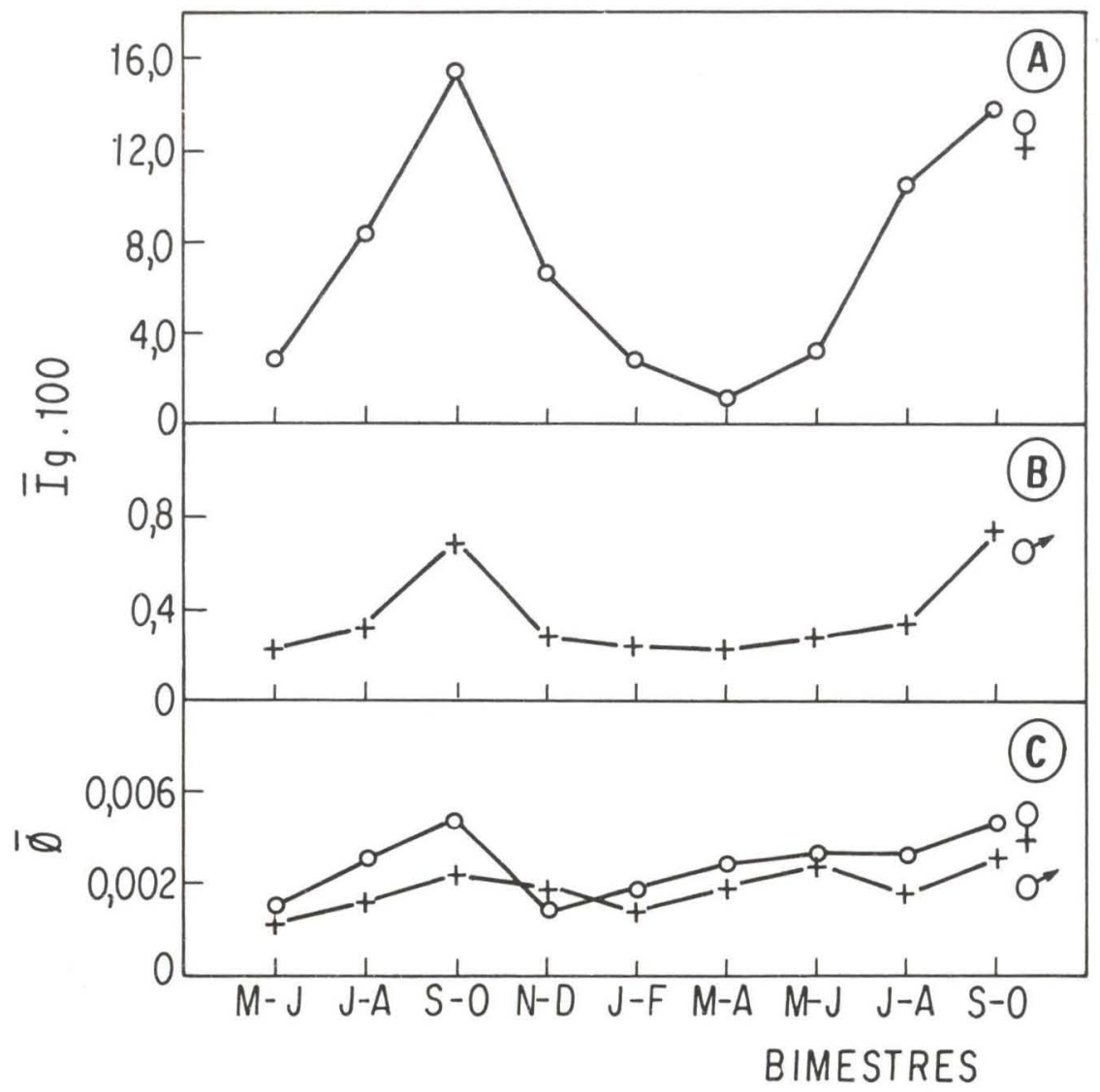

Fig. 1. Distribuição bimensal do Índice gonadossomático médio (Ig de fêmeas (A), machos (B) e do) fator de condição (C).

O tamanho de primeira maturação gonadal (Lpm) foi estimado em $10,1 \mathrm{~cm}$ para machos e $8,47 \mathrm{~cm}$ para fêmeas (Fig. 3), quando os exemplares atingem o segundo ano de vida (Fig. 4). A partir do terceiro ano de vida todos os exemplares estão aptos à reprodução. Essa estimativa tem sido utilizada no estabelecimento de normas visando a preservação da espécie.

O parcelamento da desova observado em grande número de espécies tropicais é, segundo NIKOLSKY (1963, 1969), uma adaptação para evitar a 


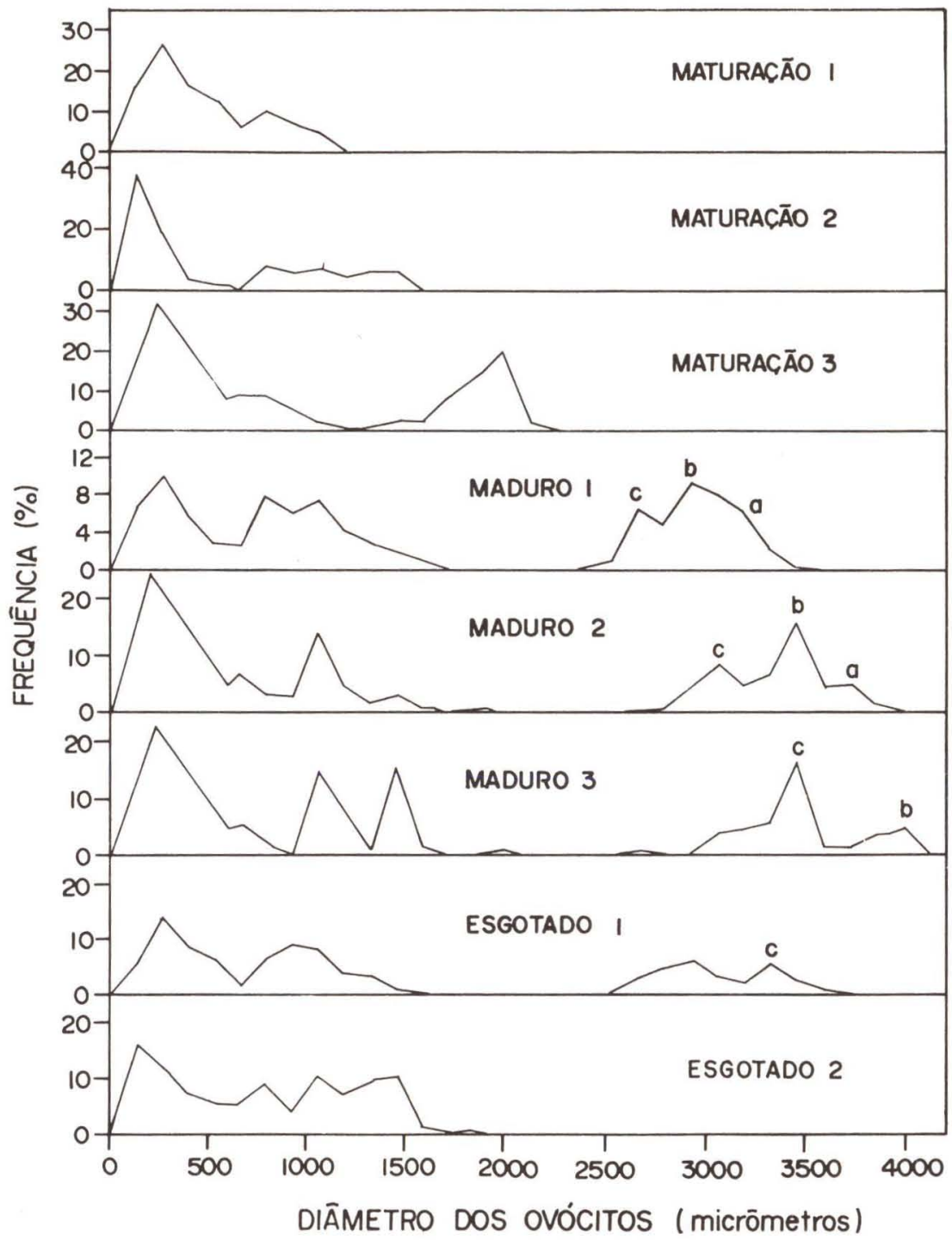

Fig. 2. Representaçào grática da distrihuição de freqüência relativa de diâmetros de ovócitos em diferentes estádios de desenvolvimento (a, b, e=lotes de ovócitos vitelinados).

competição pelo local e pelo alimento das larvas. No entanto, a obtenção precisa da fecundidade nessas espécies tem sido polêmica pela dificuldade de se distinguir os ovócitos de reserva daqueles em desenvolvimento (BAGENAL 1978) e pela dificuldade de se prever as taxas de reabsorção dos lotes de ovócitos em maturação (AgOSTINHO 1985). 


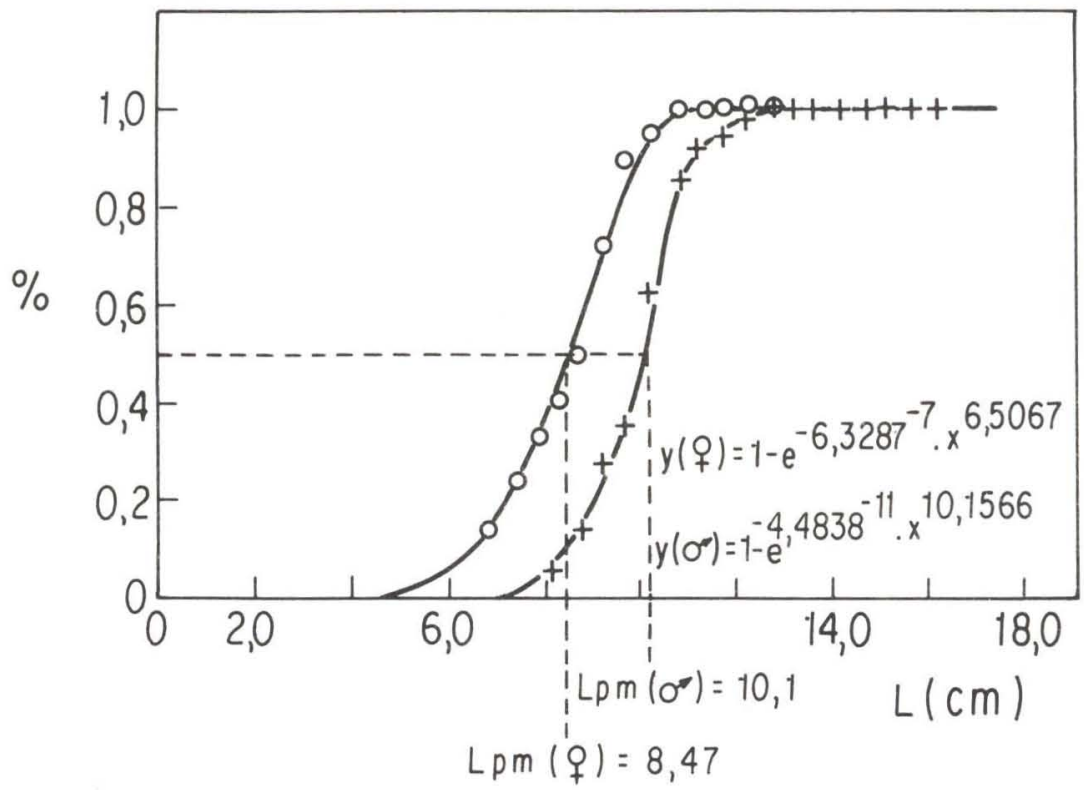

Fig. 3. Representação grálica da treqüência relativa de exemplares adultos por classe de comprimento (Lpm = tamanho de primeira maturação gonadal).

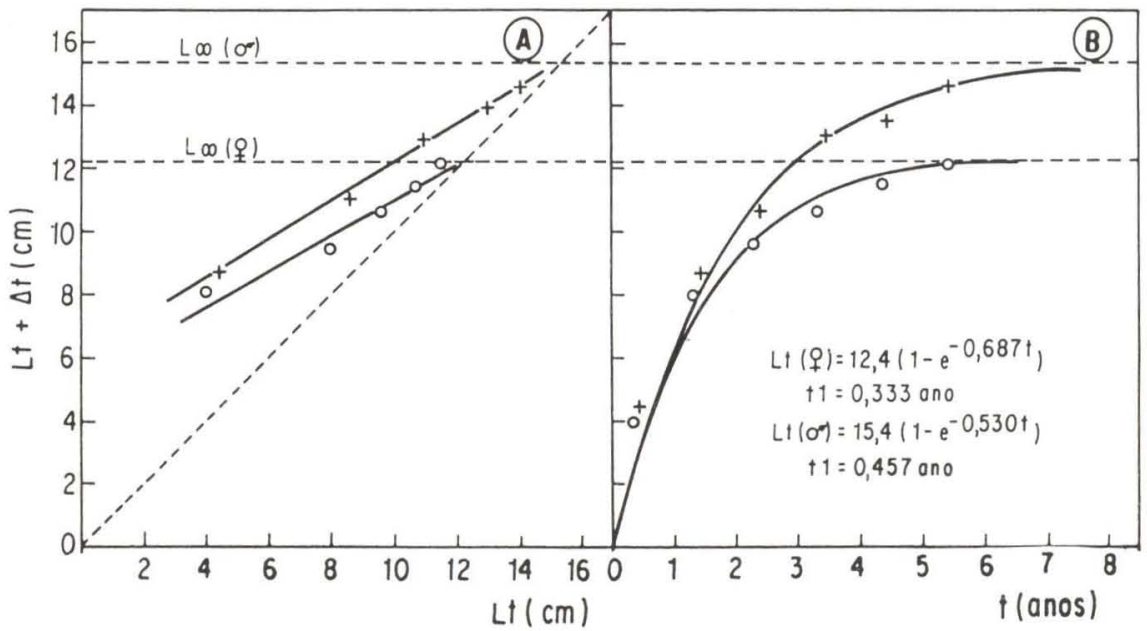

Fig. 4. Transformação Ford-Walford (A) e curvas de crescimento em comprimento (B) ajustadas pela expressão de Bertalanffy. 


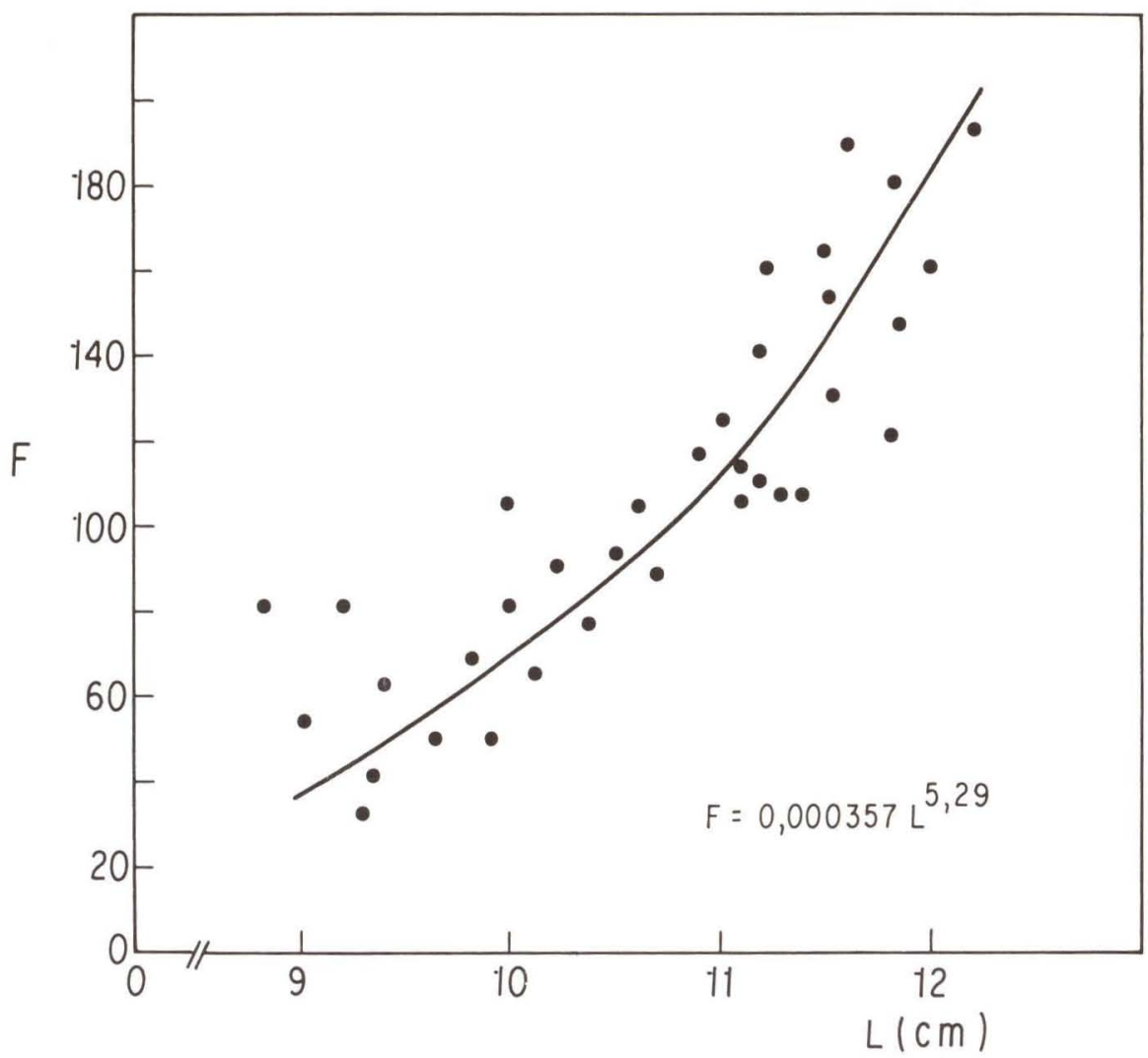

Fig. 5. Relação fecundidade/comprimento total das fêmeas.

GODINHO et al. (1977), BARBIERI (1981) e CARAMASCHI (1979) sugerem a contagem dos ovócitos vitelinados (maduros e em final de maturação) presentes nos ovários antes da desova.

No presente trabalho adotou-se a metodologia sugerida por estes autores acima citados, optando pela contagem de todos os ovócitos por serem em pequeno número e de diâmetro grande.

Rineloricaria latirostris é uma espécie de baixa fecundidade (em média 113 ovócitos) e parece não dispensar cuidados à prole, contrariando o Princípio de LAGLER et al. (1977), segundo o qual existe relação inversa entre fecundidade e cuidados parentais. O mesmo comportamento foi observado por BARBIERI (1981) para Gymnotus carapo (Linnaeus, 1758) da Represa do Lobo (São Paulo). A fecundidade foi relacionada com o comprimento total (Fig. 5), peso total (Fig. 6A) e peso dos ovários (Fig. 6B), resultando relação exponencial com a primeira variável e linear com as outras duas. O comprimento é a variável que melhor se relaciona com a fecundidade, seguindo o comportamento da maioria de teleósteos de águas continentais. 


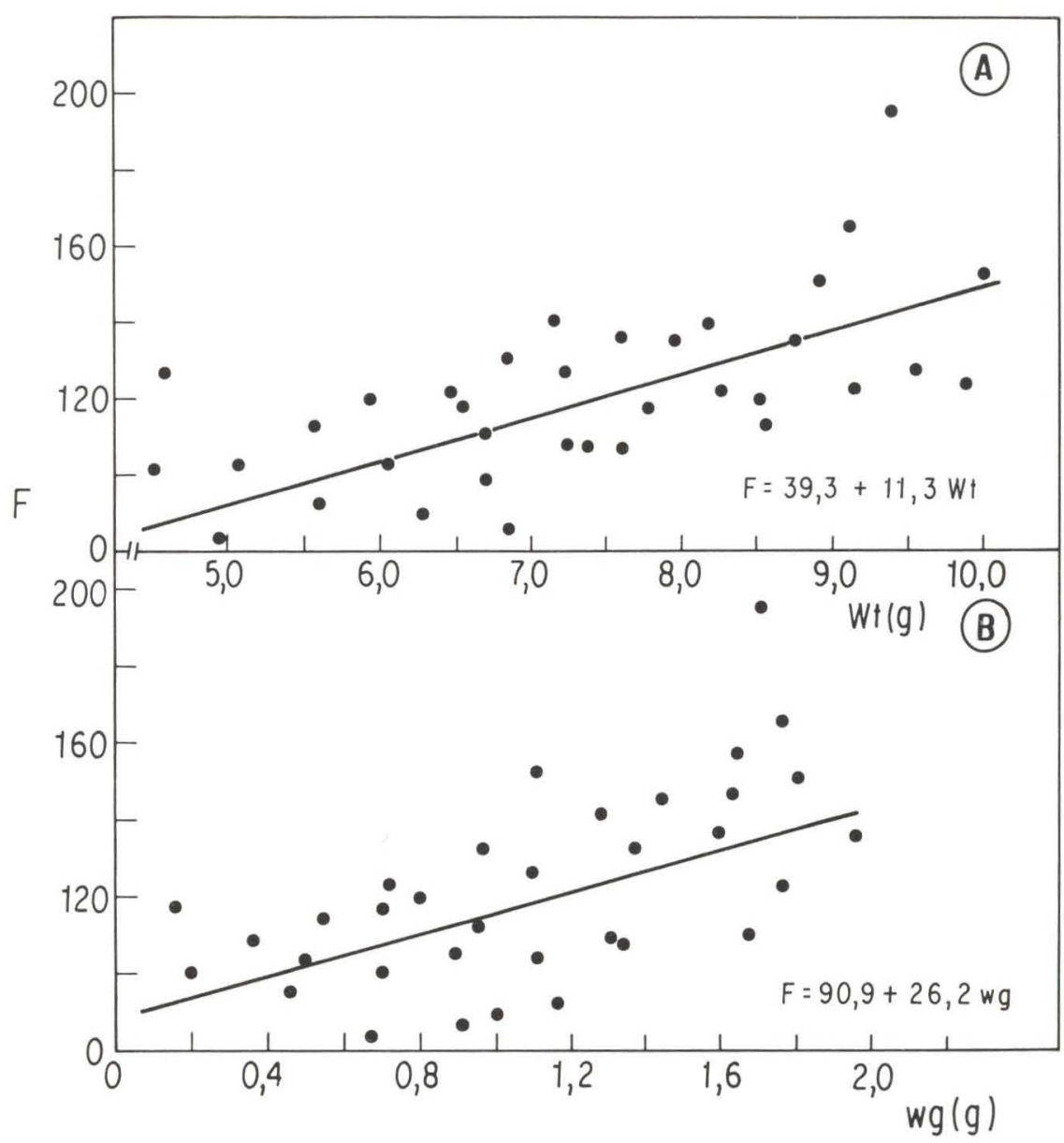

Fig. 6. Relação fecundida/peso total das Ẽ̂méas (A) e relação fecundidade/peso dos ovários (B).

\section{CONCLUSÕES}

De acordo com os objetivos propostos no presente trabalho pode-se concluir que o "cascudo-viola", Rineloricaria latirostris, do rio Passa Cinco (Ipeúna, São Paulo) apresenta o seguinte comportamento: o período de reprodução é longo, compreendido entre os meses de julho-agosto e novembro-dezembro e com maior intensidade reprodutiva nos meses de setembro-outubro. A desova é do tipo parcelada, com três lotes de ovócitos vitelinados. Os ovócitos maduros possuem diâmetro ao redor de $4000 \mu \mathrm{m}$. A fecundidade é baixa (em média 113 ovócitos). O tamanho de primeira maturação gonadal foi estimado em $10,1 \mathrm{~cm}$ para machos e $8,47 \mathrm{~cm}$ para fềmeas. Machos e fềmeas atingem a primeira maturidade no segundo ano de vida. Todos os exemplares estão aptos à reprodução a partir do 
terceiro ano de vida. A fecundidade relaciona-se exponencialmente com o comprimento total da fêmea e linearmente com o peso da fềmea e peso dos ovários. O comprimento é a variável que melhor se relaciona com a fecundidade.

AGRADECIMENTOS. O autor agradece ao Conselho Nacional de Desenvolvimento Científico e Tecnológico (CNPq) pelo auxílio fornecido à execução do trahalho.

\section{REFERÊNCIAS BIBLIOGRÁFICAS}

Agostinho, A.A. 1985. Estrutura da população, idade, crescimento e reprodução de Rhinelepis aspera (Agassiz, 1829) (Osteichthyes, Loricariidae) do rio Paranapanema, São Paulo. Tese de Doutorado, não publicada, Universidade Federal de São Carlos, São Paulo, 231 p.

Angelescu, V. \& F.S. GNERI. 1949. Adaptaciones del aparato digestivo al regimen alimentício en algunos peces del rio Uruguai y del rio de La Plata. Rev. Inst. Nac. Invest. Cien. Nat. 1: 161-281.

Bagenal, T.B. 1978. Aspects of fish fecundity, p.75-101. In: S.D. GERKING (ed.). ecology of freswater fish production. Oxford, Blackwell Scientific Publications.

BARBIERI, M.C. 1981. Contribuição ao estudo da biologia de Gumnotus carapo (Linnaeus, 1758) na represa do Lobo, Estado de São Paulo (Pisces, Ostariophysi, Gymnotidae). Tese de Doutorado, não publicada, Universidade Federal de São Carlos, São Paulo, 167p.

BARBIERI, G. \& M.C. BARBIERI. 1992. Tamanho de primeira maturação gonadal, tipo de desova e fecundidade do cascudo, Hypostomus sp.1 (Siluriformes, Loricariidae) do rio Passa Cinco, Ipeúna, SP. An. Sem. Reg. Ecol. 7: 10.

BARBIERI, G. \& VERANI, J.R. 1987. O fator de condição como indicador do período de desova em Hypostomus aff. placostomus Linnaeus, 1758 (Osteichthyes, Loricariidae) da represa do Monjolinho, São Carlos. Cienc. Cult. 39 (7): 655-658.

Barbieri, G.; M.C. Barbieri; J.R. Verani \& N. Fenerich-Verani. 1988. Ciclo reprodutivo e primeira maturação gonadal de Hypostomus aff. plecostomus Linnaeus, 1758 da represa do Monjolinho, São Carlos, SP (Teleostei, Loricariidae). Notas preliminares. An. Sem. Reg. Ecol. 6: 125-144.

BertalanfFy, L. VON. 1938. A quantitative theory of organic growth. Humam Biology 10 (2): 181-213.

Braga, F.M.S. DE; M.A.A.S. DE BRAGA \& R. GoItein. 1985. Fator de condição e alimentação de Paralonchurus brcsiliensis na região da Ilha Anchieta (Lat.

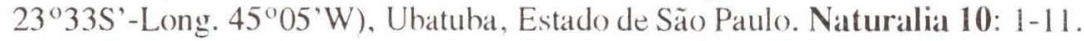

Britski, H.A. 1972. Os peixes de água doce do Brasil, p.79-108. In: COMISsÃo Inter-Estadual da Bacia Paraná-Uruguai (ed.) Poluição e Piscicultura. São Paulo, USP-Instituto de Pesca do Estado de São Paulo.

Britski, H.A.; Y. Sato \& A.B.S. Rosa. 1988. Manual de identificaçãoo de peixes da região de Três Marias, Minas Gerais. Codevasf, 115 p. 
CARAmaschi, E.M.P. Reprodução e alimentação de Hoplias malabaricus (Bloch, 1794) na represa do rio Pardo (Botucatu, SP) (Osteichthyes, Cypriniformes, Erythrinidae). Dissertação de Mestrado, não publicada, Universidade Federal de São Carlos, São Paulo, 144p.

Fenerich, N.A.; M.Y. Narahara \& H.M. Godinho. 1975. Curva de crescimento e primeira maturação sexual do mandi, Pimelodus maculatus Lac., 1803 (Pisces, Siluroidei). Bol. Inst. Pesca, Santos, 4 (1): 1-28.

GERI, J. 1969. The freswater fishes of South America, p.828-848. In: E.J. FITTKAU (ed.). Biogeography and ecology in South America. Hague, Amsterdã, Dr. Junk N.V. Publications.

GNERI, F.S. \& V. ANGelescu. 1951. La nutricion de los peces iliofagos en relacion con el metabolismo general del ambiente acuatico. Rev. Inst. Nac. Invest. Cien. Nat. 2 (1): 1-44.

Godinho, H.M.; M.A. Basile-Martins; N.A. Fenerich \& M.Y. Narahara. 1977. Fecundidade e tipo de desova do mandi, Pimelodus maculatus Lac., 1803 (Pisces, Siluroidei). Rev. Bras. Biol. 37 (4): 737-744.

Lagler, K.F.; J.E. Bardach; R.R. Miller \& D.R. Passino. 1977. Ichthyology. New York, John Wiley \& Sons, 506p.

LE CREN, E.D. 1951. The length-weight relationship and seasonal cycle in gonad weight and condition in the perch Perca fluviatilis. J. Anim. Ecol. 20 (2): 201-219.

Lowe-McConnell, R.H. 1975. Fish communities in tropical freshwater. London, Logman Inc., 337p.

MCGREGOR, J.S. 1959. Relation between fish condition and population size in the sardine (Sardinops caerulea). Fishery Bull. Wildl Serv. U.S. 60 (166): 215-230.

Moreira-Filho, O. 1983. Estudos na família Parodontidae (Pisces, Cypriniformes) da Bacia do Rio Passa Cinco - SP. Aspectos citogenéticos e consideraçñes correlatas. Dissertação de Mestrado, não publicada, Universidade Federal de São Carlos, São Paulo, 212p.

Narahara, M.Y. 1983. Estrutura da população e reprodução de Rhamdia hilarii (Valenciennes, 1840) (Osteichthyes, Siluriformes, Pimelodidae). Tese de Doutorado, não publicada, Universidade de São Paulo, São Paulo, 226p.

NiKOLSKY, G.V. 1963. The ecology of fishes. London, Academic Press, 352p. . 1969. Theory of fish population dynamics. Edinburgh, Oliver \& Boyd Ltd., 323p.

RICKER, W.E. 1971. Methods for assessment of fish production in freshwaters. Oxford, Blackwell Scientific Publications, 348p.

SANTOS, E.P. DE. 1978. Dinâmica de populações aplicada à pesca e piscicultura. São Paulo, Hucitec-EDUSP, 129p.

SimpSON, A.C. 1951. The fecundity of the plaice. Fish. Investig. 2/17 (5): 1-27. 1959. Method used for separating and counting the eggs in fecundity studies on the plaice (Pleuronectes platessa) and hering (Clupea harengus). 
Occasional paper 59 (12): 1-3.

Vazzoler, A.E.A.M. 1981. Manual de métodos para estudos biológicos de populações de peixes. Reprodução e crescimento. Brasilia, CNPq-Programa Nacional de Zoologia, 108p.

VAZZOLER, A.E.A.M. \& G. VAZZOLER. 1965. Relation between condition factor and sexual development in Sardinella aurita (Cuv. \& Val.). Anais Acad. bras. Cienc. 37 (supl.): 353-359.

WALFORD, L.A. 1946. A new graphic method of describing the growth animals. Biol. Bul. mar. biol. Lah., Woods Hole, 90 (2): 141-147.

Recebido em 10.XII.1993; aceito em 13.VII.1994. 